\title{
Costs for conventional and renewable fuels and electricity in the worldwide transport sector: a mean-variance portfolio approach ${ }^{1}$
}

\author{
Ricardo Guerrero-Lemus ${ }^{1}$, Gustavo A. Marrero² ${ }^{2}$ and Luis A. Puch ${ }^{3}$.
}

(1) Departamento de Física Básica, Av. Astrofísico Francisco Sánchez s/n, Universidad de La Laguna, 38206 S/C de Tenerife, SPAIN.

(2) Departamento de Análisis Económico, Campus de Guajara, Universidad de La Laguna, 38071 S/C de Tenerife, SPAIN.

(3) Departamento de Economía Cuantitativa, Universidad Complutense de Madrid, Campus de Somosaguas, 28223 Madrid, SPAIN.

\begin{abstract}
In this paper we analyze the role of changes in the fuel mix on emissions reduction and the diversification of risks associated to rising prices of energy. To this purpose we evaluate the average cost and the cost volatility of alternative fuel combinations in the road transport sector by means of the Mean-Variance Portfolio Theory. The results suggest big gains in diversification of risks and emissions reduction associated with shifts away the current fuel mix, which is more than $90 \%$ concentrated worldwide in fossil fuels. Those shifts are discussed vis à vis the policy recommendations of the International Energy Agency on fuel use in the transport sector, and both the business as usual and the low carbon scenarios of the European Commission. In particular, shifting toward an efficient system would involve optimizing the use of biofuels (mostly from endogenous feedstock), with second generation biofuels taking the lead in the long-run, and this combined with electricity from clean sources. This scenario would mean reducing cost volatility by more than $50 \%$ as well as $\mathrm{CO}_{2}$ emissions by more than $30 \%$ in the long-run.
\end{abstract}

Key words: Fuel costs, road sector, efficiency frontiers, mean-variance analysis

\footnotetext{
${ }^{1}$ We thank Manuel A. García for excellent research assistance. We also thank the Editor and three anonymous referees for very helpful comments and suggestions. Puch and Marrero thanks Dirección General de Investigación through projects ECO2010-17943 and ECO2009-10398, respectively.
} 


\section{Introduction}

Oil is the main energy input for the transport sector around the world [1]. Current alternatives to fossil fuels are mainly liquid biofuels (henceforth biofuels) and electricity, but these as well as other substitutes for oil can be still considered residual. Such a scenario is expected to change in the near future towards a fuel mix more balanced among the various energy sources [2]. The process is not at all free of uncertainties, from demand and supply challenges in the oil market to regulatory instability and factors related to energy security [3]. Further, climate change concerns cannot be disregarded in relation to sustainable alternatives to oil consumption in the transport sector, and these concerns imply taking into account the uncertainty about $\mathrm{CO}_{2}$ emission costs. Whereas the electricity sector seems in a stage of somewhat an efficient managing of aggregate risks [4], this does not appear to be the case at all for the road transport sector which is particularly exposed to oil price shocks.

In this paper we analyze the role of changes in the energy mix of the road transport sector on the diversification of fuel risks. The contribution of the paper is to evaluate the average cost and the cost volatility of alternative fuel combinations by means of the Mean-Variance Portfolio Theory [5, 6]. This theory has been widely used in finance and subsequently applied to the energy industry with regard to electricity generation [7-9], also under specific geographic and climatic features [10]. The idea is that not only the average cost of each alternative should be considered, but also the associated risk, measured in terms of the aggregate fluctuations of production costs. Among the different costs, this literature assumes that fluctuations in energy production costs are mostly determined by the volatility of the associated feedstock prices, and that fuel prices are by far the key factor in shaping a fuel portfolio designed to minimize risks [7, 8]. Also, the relevant exercise is not the individual study of the different alternatives, but rather the joint evolution of all of the options conforming a fuel portfolio (or mix). Hence, we focus on feedstock prices volatilities and their correlations to measure the overall fuel portfolio risk.

While several authors have already built upon mean-variance portfolio analysis for electricity generation, we are not aware of existing papers discussing the risk management for conventional and renewable fuels in the transport sector. Rather, studies on fuel alternatives for the transport sector generally consider energy costs and 
prices excluding the risk associated with fluctuations in fossil fuel prices, and often focus on stand-alone comparisons between alternative fossil fuels and biofuels [11-12] or between first and second generation biofuels [13]. In addition, there exists an extensive literature studying the cost-effectiveness of different transport scenarios, generally related with fuel switching or shifting in means of transportation [14-16]. ${ }^{2}$ Using a mean-variance approach, our paper solely focuses on fuel switching in private vehicles, leaving aside its complex relationship with changes in modes of transport or with subsidies/tax policies.

A change in the modes of transport (e.g. considering a public bus rapid transit system or non-motorized options) or the development of rail infrastructures are important drivers of transport scenarios [17]. Investments towards plug-in EDVs (electric drive vehicles) together with G2V (grid-to vehicle) and V2G (vehicle-to-grid) improved abilities to charge the EDVs from the grid can lead to a more integrated power and transport system [18] Tax policies can make 2nd generation (2G) biofuels technology market competitive [19]. Not taking into consideration these elements may limit the scope of our results, especially for the medium and long run. We comment on those limitations below. However, we consider our approach overly useful to quantify important dimensions of risk management in the road transport sector. In particular, diversification away from fossil fuels brings about important risk (cost volatility) reduction without affecting the average cost of the entire fuel portfolio. It turns out that such a diversification leads also to emissions reductions which magnitude depends upon the costs of $\mathrm{CO}_{2}$ as we show.

Another important contribution of the paper is that the most up to date available information on production costs of the various fuel technologies for the transport sector is used. We combine such information with reliable forecasts for the evolution of the technologies and prospective global scenarios. In order to specify a simple and unified framework, we mostly use results and recommendations from the International Energy Agency (IEA). However, more elaborated specifications could be defined, possibly

\footnotetext{
${ }^{2}$ Most of these papers conclude that fuel-based solutions achieve important $\mathrm{CO}_{2}$ reductions, but their costs are significantly higher than policies inducing shifts from high-emitting sources (private vehicles) to lower-emitting sources (public transport and non-motorized options). A full in-depth analysis of modes of transport that might substitute or complement private vehicles within our mean-variance approach would go beyond the scope in this paper.
} 
combining data from different sources. Finally, all costs are measured in dollars per kilometer (USD/km) for a comprehensive comparison.

The mean-variance fuel portfolio analysis is studied under four alternative stylized scenarios: high and low prices of crude oil, both in the short and in the long run. Motivated by technological and feasibility constraints, two main issues distinguish the short and the long term scenarios. First, the capacity of biofuels to reduce their costs according to their learning curves. Second are the upper bound restrictions assumed for the shares of biofuels and electricity, which are much smaller for the short-run than for the long-run scenario. In addition, we consider an extension with different assumptions on $\mathrm{CO}_{2}$ emissions costs. Fuel efficiency frontiers are estimated for these alternative scenarios. The efficient fuel generation frontier is then compared with the business as usual (BAU) mix expected by the European Commission in the short (the current mix) and the long run (by 2050). Further, the efficient frontier in the long-run scenario is also compared with the low carbon roadmap mix targeted by the European Commission by 2050 [20]. In this way, we can evaluate the BAU and the 2050 target in terms of our estimated efficiency portfolios. $^{3}$

The paper is organized as follows. Section 2 describes the background for the question at hand together with the theoretical framework for Mean-Variance Portfolio Theory. Section 3 organizes the evidence and reports the consensus figures for fuel costs and fuel use prices. Section 4 implements the estimation of efficiency frontiers on the available data by using the average costs taken from the IEA. The last section concludes and proposes lines for future research.

\section{Methodology}

A mean-variance analysis of the fuel mix enables an efficiency frontier to be defined for the fuels used in the road transport sector. A fuel mix can be interpreted as a fuel portfolio. This is given by a set of weightings, each between zero and one, of all feasible

\footnotetext{
${ }^{3}$ Europe appears to be leading low carbon energy policies around the world, for overall emissions [21, 22] but also for the transport sector [23]. We have recently seen announces of similar energy policy for the transport sector by countries as the US, Brazil, Mexico or China. See Ref. [15] for a discussion of emissions mitigation policies in the transport sector in developing countries. Thus, although European policy is our precise reference in this paper, our analysis should be seen for a global (worldwide) context.
} 
fuel alternatives. Those weightings, say $X_{1}, \ldots, X_{n}$, must always add up to unity, and are subject to certain technological restrictions that determine the range of variation of each fuel in the portfolio under alternative scenarios. For instance, depending on whether we consider the short or the long-run, we will assume different technical restrictions. These restrictions are discussed in Section 3 below, together with a description of all the data required for the analysis. Thus, given those weights, the average cost of the energy portfolio is defined as the weighted average of the various individual costs:

$$
\overline{C C}=\sum_{i=1}^{n} X_{i} \cdot \overline{C_{i}}
$$

It is clear from this expression that, given the technological restrictions, the minimum average cost of the fuel mix will correspond to a combination of the less expensive technologies.

The other key element needed to characterize the efficient frontier is the volatility of each feasible fuel portfolio. The year-to-year variance of historical data is the usual way of measuring risk [24-25]. For each fuel technology, the risk would be ideally calculated by using a measure of the dispersion of its costs. This cost dispersion may depend on many factors, such as the variability in the feedstock price [26-27], the operation and maintenance cost of the fuel technology, the investment risk of the distribution infrastructure, or the costs related to the potential instability of regulation. But also, the cost dispersion depends on all cross correlations among the aforementioned costs as explained below. Our benchmark focuses on the feedstock price volatility, which is the most relevant volatility for the road transport sector. Moreover, from the point of view of the society, the important risk is the one related to the whole fuel mix. Therefore, to better understand the variance expression for the mix (the measure of volatility used), let us assume only two technologies, A (say, gasoline - diesel) and B (say, second generation biofuel). In such a particular case, the variance of the mix can be described from the following expression:

$$
\operatorname{Var}(\operatorname{mix})=X_{A}^{2} \cdot \operatorname{Var}\left(C_{A}\right)+X_{B}^{2} \cdot \operatorname{Var}\left(C_{B}\right)+2 \cdot X_{A} \cdot X_{B} \cdot \operatorname{cov}\left(C_{A}, C_{B}\right) .
$$

Though this is a well-known expression, it is highly illustrative. The estimating volatility of a fuel portfolio depends on individual variances weighted by the square of 
their weightings, but it also depends on how their costs evolve together (their cost covariance matrix). Thus, the lower the correlation between the costs of $\mathrm{A}$ and $\mathrm{B}$, the lower the volatility of combining both alternatives in the fuel portfolio. Note, for instance, that if the covariance is highly negative (associated with a correlation close to -1), the variance of the fuel mix could be almost negligible [7]. Unfortunately, unlike with financial assets, it is unrealistic to assume negative correlations among the costs of different fuel generating technologies. Clearly though, by looking to the whole mix and combining fuel technologies with low correlations, energy policy can achieve the goal of lowering the risk of the fuel portfolio.

Once the average cost and risk of a fuel portfolio are determined, an efficient mix is defined by a set of weights for the various alternatives considered. For a given level of the average cost, such an efficient mix will minimize the volatility over every feasible combination given technological restrictions. The set of all efficient portfolios comprises what is known as the Efficient Frontier. Figure 1 shows a hypothetical efficient frontier. The average cost is along the $y$-axis, and the measure of risk along the $x$-axis. The minimum cost (MC) mix includes the cheapest technologies. Starting from this mix, if we move left along the frontier, more diversified portfolios would presumably increase the average cost while simultaneously reducing the variance until what is known as the minimum variance (MV) mix is reached. Given the technologies involved and the restrictions assumed, being to the left of the frontier is unfeasible, while any portfolio above the MV or to the right of the frontier will be inefficient.

An alternative efficiency mix would be in between the MC and the MV portfolios in what can be labeled a MC-MV portfolio. Also, the estimated frontier allows an assessment of specific portfolios and offer directions for improvement. Whenever two portfolios with either the same risk but lower cost or the same cost but lower risk, each respectively moving closer to the frontier with respect to some inefficient reference portfolio, can be defined, any combination of them is more efficient than the reference portfolio. That kind of result could be explored for more specific policy proposals than those discussed in this paper. Rather, we elaborate below throughout the MC, MV and MC-MV combinations based on specific fuel alternatives that are feasible and foreseen. The relevant combinations are chosen in accordance to the current evidence and the 
prospects on the evolution of the costs of the different fuel technologies. We characterize such an evidence and prospects in detail throughout the next section.

\section{Experimental}

This section revises the baseline alternative technologies in the fuel mix, together with their costs. First, we briefly comment on the alternative technologies and scenarios considered so as to introduce the technological restrictions that are central for the meanvariance portfolio analysis. Second, we describe current and expected average production costs of the considered technologies, mostly on the basis of the available information from the IEA. A discussion on the costs associated to $\mathrm{CO}_{2}$ emissions for each fuel alternative is included, and all the costs are transformed into dollars per kilometer (USD/Km) for a comprehensive comparison. Finally, we use the evolution of feedstock prices to characterize individual volatilities and their cross correlations, which are the essential parameters to compute the risk measure for any fuel portfolio.

\subsection{Alternative scenarios, technological restrictions and the fuel mix}

We focus on the following fuel alternatives: $i$ ) conventional fossil fuels (a combination of gasoline and diesel), ii) first and second generation biofuels, and iii) electricity. For first generation biofuels $(1 \mathrm{G})$, we consider the most reliable fuels in terms of production costs and carbon emission per liter produced: ethanol from sugar cane and rapeseed biodiesel. Likewise, for second generation biofuels (2G), we consider ethanol from cellulose and BtL as biodiesel.

The use of biofuels is growing, with an estimated world production of $90 \mathrm{Gl}$ in 2008, but only represents a $3.5 \%$ of the fossil fuel transportation consumption on a volumetric basis. 2G biofuels are now important challengers for the oil industry supremacy but still seem far from becoming operational in the mix determination at a commercial level. 2G biofuels do not compete for farmland [28] and the carbon emissions from their production processes are diminished to a large extent compared to $1 \mathrm{G}$ biofuels [12]. However, only a $2 \mathrm{G}$ generation commercial plants are just starting to produce and the prospects for production growth are not particularly encouraging [12]. Finally, 
according to the most recent data, the use of electricity in the transport sector can be still considered as residual (23 MToe as for 2009). ${ }^{4}$

Therefore, a fuel portfolio will be composed of the following set of weights: $X_{1}$ is the percentage used as conventional fossil fuels, $X_{2}$ is the share of sugar cane ethanol, $X_{3}$ is for rapeseed biodiesel, $X_{4}$ is for $2 \mathrm{G}$ cellulosic ethanol, $X_{5}$ is for $2 \mathrm{G}$ BtL biodiesel, and $X_{6}$ is the weight assigned to electricity. These weights add up to one and are subject to several technical restrictions that are justified below in connection with some very stylized alternative scenarios.

Consequently, throughout the paper we will consider four stylized alternative scenarios. These scenarios are mostly based on the prospective analysis carried out by the IEA. On the one hand, we focus on either a short- or a long-run scenario. On the other hand, we consider both a low and a high oil price scenario. Predictions for the oil prices (in real terms) that may prevail by 2030 comprise levels as low as USD $_{2009} 30 / \mathrm{bbl}$ [32].

However, more recent scenarios such as the IEA's World Energy Outlook 2008 assume an average price of $\mathrm{USD}_{2009} 100 / \mathrm{bbl}$ until 2015, followed by a linear rise to reach more than USD $_{2009} 120 /$ bbl by 2030 [33]. Given the broad span of prices, we consider a high uncertainty regarding the future trends in the oil price. Further, this uncertainty leads to the absence of reliable oil price scenarios beyond year 2030. Therefore, we implement two oil price scenarios: $U_{S D} 200960 / b b l$ and USD $_{2009} 120 / \mathrm{bbl}$. In light of the aforementioned predictions we think our high oil price scenario is moderate, insofar oil prices at as high as USD 2009 199.95/bl for 2035 are considered only in some high risk scenarios [34].

As feasibility restrictions, we impose lower and upper bounds for the weights $X_{1}$ to $X_{6}$, that vary depending on whether the short or the long-run scenarios are specified. We assume, however, that those technological restrictions are the same for the low and high oil price environments. This latter assumption is justified by the low short-run elasticity of energy use to energy price changes estimated from time series data for different

\footnotetext{
${ }^{4}$ We exclude other, less established, fuel alternatives for the road transport sector, due to technical immaturity and a lack of suitable data required for a mean-variance portfolio analysis. In particular, among $3 \mathrm{G}$ biofuels, algal biofuels exhibit several attractive features but their short term perspectives are not robust enough to consider it mature for a significant role in fuel supply for the transport sector [28]; biomass-to-hydrogen production has some perspectives but the costs are still high [29-30], and the dropin biofuels need substantial research ahead to reach the market [31].
} 
OECD countries [35]. Such a low short-run elasticity seems to reflect sizeable adjustment costs of the energy technology over short time spans [36, 37].

For the short-run scenario, we allow the share of fossil fuels, $X_{1}$, to range between $70 \%$ and $100 \%$. The $70 \%$, though it is an ad-hoc assumption, attempts to reflect the idea about the recognized dominance of fossil fuels in the market at least in the short-run [2]. The weight for sugar cane ethanol, $X_{2}$, ranges from 0 to $10 \%$, since we consider the technical blend limitations in conventional gasoline engines but at the same time a rising market in flexible fuel vehicles (up to $100 \%$ ethanol). On the contrary, by considering just the technical blend limitations in conventional diesel engines (up to 5\% biodiesel [38]), the weighting for rapeseed biodiesel, $X_{3}$, is assumed to range from 0 to $5 \%$. As restrictions for $2 \mathrm{G}$ biofuels are also stringent in the short-run, we consider $X_{4}$ and $X_{5}$ to range between 0 and $5 \%$. Finally, we assume that $X_{6}$, the weight for electricity, will range between 0 and 10\%, because of the huge investment that would be required for electric vehicles refueling and the still high cost of batteries in terms of USD/kWh. These issues would make the electric car hardly competitive without subsidies in the short-run.

For the long-term scenario (2040-2050) our restrictions are less stringent, and we assume the following: $X_{1}$ is between $25 \%$ and $100 \%$, as it is completely realistic that at least a minimum share of energy consumed in the road transport sector will come from fossils fuels yet in the long-run [39]; the weights for sugar cane and 2G bioethanol ( $X_{2}$ and $X_{4}$ ) range between 0 and $50 \%$ as bioethanol can be only blended with gasoline; the weights for rapeseed biodiesel and BtL $\left(X_{3}\right.$ and $X_{5}$ ) range between 0 and $20 \%$ as higher blends can seriously damage the engine [38] and produce health concerns [39]. Finally, $X_{6}$ is assumed to be between 0 and $50 \%$, as the electric car is expected to be competitive in the long-run without subsidies, but it is still not reliable for long distances in isolated areas. These boundary conditions are qualified in connection with the intrinsic limitations of our approach associated with any long-term evaluations. Finally, for the ease of exposition, we omit at first the important restriction that alternative emission trading schemes (ETS) might impose on fuel efficiency in the near future. Thus, changes in the price of $\mathrm{CO}_{2}$ emissions will be considered apart afterwards. 


\subsection{Individual average production cost}

Average production costs for the alternative fuels considered are obtained from the IEA in terms of USD $_{2009}$. Production costs are measured in US Dollar per Brent barrel $\left(\mathrm{USD}_{2009} / \mathrm{bbl}\right)$, but they will be transformed into $\mathrm{USD}_{2009}$ per kilometer for a more comprehensive comparison. When needed, as production costs/price data of different countries are involved, official exchange rates obtained from the European Central Bank (ECB) [40] have been used, in particular for the EUR/USD exchange rate. Also, (once everything is in nominal USD) real prices are obtained as ratios over the yearly US GDP Deflator, as reported in ECB data.

To determine the gasoline and diesel costs we have obtained the shares of the average gasoline and diesel prices in the US coming from crude oil, federal and state taxes, refining costs and profits, and distribution and marketing costs [41]. Then, to calculate the gasoline and diesel costs (Table 1), we have only considered the crude oil and refining costs.

On the other hand, there is a wide range of estimations for biofuel production costs [4246]. To some extent the different values correspond to regional differences (affecting labor costs or climatic and land conditions), the treatment of benefits obtained for byproducts, or the differences in the pathways considered (minor). However, the production costs of first generation biofuels largely depend on feedstock prices. With feedstock prices having experienced a drastic surge in recent years followed by a decline afterwards [42], biofuel production costs vary significantly across years. To simplify the treatment of the data, the biofuels costs are taken from the single IEA reference source [47] and organized as averaged and updated values (see Table 1).

A decrease in production costs for $1 \mathrm{G}$ biofuels due to learning effects is assumed to be limited, given the maturity of both the conversion processes and the cultivation of feedstock. Besides, economies of scale due to larger plant sizes will be counteracted by more complicated logistics and increased transport costs [17]. Learning plays an important role for the market introduction of advanced 2G biofuels instead. Consequently, important cost reductions can be expected both in terms of the production process due to economies of scale and an increasing maturity of processes and components $[1,17]$ in the case of $2 \mathrm{G}$. 
For the average values of electricity in the transport sector, first we have considered the range of 2009 electricity prices for the household sector in the G7 countries, as reported in the 2010 IEA Key World Energy Statistics. The values range from 0.1155 $\mathrm{USD}_{2009} / \mathrm{kWh}$ in the US to $0.2842 \mathrm{USD}_{2009} / \mathrm{kWh}$ in Italy. Also we have considered the forecasts in residential electricity prices as reported by the US Department of Energy. These forecasts involve a long-term $0.93 \%$ rise of electricity prices in a reference scenario, a $7.48 \%$ rise in a high coal costs scenario, and a 33.64\% rise in a global greenhouse gas (GHG) priced scenario, all in terms of $\mathrm{USD}_{2009}$ [34]. Consequently, in this work we consider the high coal costs scenario as a benchmark, and the variances of the electricity price limited by the reference and the GHG priced scenario.

Finally, in terms of the costs per kilometer, we have used as a reference value the fuel consumption characteristics of the most efficient midsize car models (Toyota Prius for gasoline car, Chevrolet Malibu for flexible fuel car and Volkswagen Golf for diesel car) published in the 2012 Fuel Economy Guide of the U.S. Department of Energy and the U.S. Environmental Protection Agency (EPA), exposed in Table 2. The same source has been used to define the electricity consumption characteristics of the most efficient middle size electric car model (Nissan Leaf). A medium-sized car is defined with a limited passenger and cargo volume of $3.11-3.37 \mathrm{~m}^{3}$. A combined estimate, city and highway kilometers per liter $(\mathrm{km} / \mathrm{l})$, is used, which assume driving 55\% in the city and $45 \%$ in the highway [38].

As flexible vehicles can use bioetanol blended with gasoline up to 85\% (E85), we will consider the E85 blend in our model. On the other hand, as diesel-vehicle manufacturers listed in the Fuel Economy Guide [38] currently approve the use of biodiesel blends of up to 5\% (B5) in their vehicles and state that vehicle damage caused by using higher blends will not be covered under their manufacturer's warranty, the biodiesel blend considered is B5.

Notice that the differences between fuels costs tend to decrease in the long-run, regardless of whether the oil price is high or low. However, convergence is more pronounced in a high oil price scenario. Again, this is an expected result due to the evolution of learning processes, decreasing returns to scale in production, and 
competitive markets. Thus, the strongest the convergence process among average production costs in the long-run, the more important the role of risks associated with costs in determining the efficiency of the fuel mix, for a given path of costs implied by the emission trading system. In the case of electricity, the reference scenario foresees a quasi-constant electricity price in $\mathrm{USD}_{2009}$, but we have decided instead to incorporate data from the scenario with a high cost of coal as a rise in the price of fossil fuel resources in the long-run is likely to occur.

It can be seen from Table 3 that electricity has a lower price per kilometer at present and in the future compared to biofuels, provided the price is kept constant. But this lower price is offset by the higher cost of acquisition for electric vehicles compared to those based on internal combustion engines. On the other hand, if the weighting of fossil fuels in the electricity mix is maintained and the price of these commodities continues to rise in the long-run, 2G biofuels will reach cost parity with electricity in the near future [19]. In any case, integrating the power and transport systems has influence on the electricity mix itself, and therefore, incorporating further interactions is needed to assess the role of electric vehicles in future road transport.

\section{3. $\mathrm{CO}_{2}$ emissions costs}

An important contribution of the paper is to consider the costs related to $\mathrm{CO}_{2}$ emissions for the different fuel alternatives in our mean-variance portfolio analysis. In Section 4, we will compare different efficient fuel portfolios when $\mathrm{CO}_{2}$ emission costs are incorporated into the analysis and when they are not.

GHG emissions avoided with different alternative fuels are reported in Table 4. The GHG emission savings from biofuels are obtained from [13] and based on updated JCREUCAR-CONCAWE reports $[43,48]$. These emission savings are originally reported in terms of \% reduction, but we translate them to $\mathrm{kg} / \mathrm{GJ}$ applying conversion factors as discussed in the literature $[29,49]$. These conversion factors are also applied to electricity.

As the evolution of $\mathrm{CO}_{2}$ emissions per kWh of electricity and the heat output over the last 15 years have been increasingly smooth at global scale [1], the imputed $\mathrm{CO}_{2}$ cost 
for electricity can be considered constant in the short-run. However, in the long-run, the IEA prediction is for a slight increase in the fossil fuels share in electricity production. Thus, in the Baseline scenario in 2050, the forecast is a share of $70 \%$ from a current $67.8 \%$ (2008), with a contribution share of renewables reaching a 22\%. Rather, the most optimistic scenario (Blue high REN scenario) considers in 2050 a fossil fuel share, without carbon capture and storage, of $10 \%$ and a renewable share up to $75 \%$ [2]. Consequently, the $\mathrm{CO}_{2}$ emitted to produce the electricity required by the electric vehicles in the long-run is very much uncertain.

\subsection{Feedstock prices: volatilities and cross-correlations}

As discussed in Section 2, computing individual cost volatilities and their crosscorrelations is a difficult task. Instead, a widely implemented alternative is to assume that fluctuations in production costs are mostly determined by the variability of the associated feedstock prices $[10,12,13]$. Although this assumption has been generally made for electricity generating cost analysis, we believe that it is an even more realistic assumption for the analysis of fuel mix, as it is our case. First, feedstock costs represent a very high percentage of the total cost of supplying fuel and it is clearly the most important cost in the production process. Second, as far as at the benchmark level we are already assuming mature technologies, the investment risk should be insurable to a large extent. Finally, OM risk has to do mostly with labor costs, which should be similar across technologies. Therefore, in this paper we take the variance-covariance values of feedstock prices as the basic reference for risk measurement.

Accordingly, the time series evolution of oil, Brazilian sugar cane (as the most competitive and important ethanol source) and rapeseed oil is specifically taken into account. Time series evidence for the prices of raw inputs for $2 \mathrm{G}$ biofuels is unfortunately not available since an international market for trade in such a feedstock has not been established. Finally, to construct the time series evidence on electricity prices we build upon the statistics at the US Department of Energy.

In order to obtain appropriate volatility and cross-correlation measures, we need first to remove the trend for the different price series. To this goal, we consider the widely used Hodrick-Precott (HP) filter [50], which is implemented over all of the annual data 
series. Figure 2 shows the cyclical parts that result from such a detrending procedure. Several facts are worth noting. The fluctuations in the price of electricity are much lower than that of the different feedstock prices considered. The main reason for this result is the already existing diversification in the generation of electricity, which reduces the volatility of its generation cost and prices. However, the magnitudes of the fluctuations of the remaining three variables are quite similar. Indeed, between 1982 and 2009, the standard deviation of the estimated cycle of the oil price is 0.21 , those of the rapeseed and sugar cane are both 0.19 , while the one of electricity prices is only 0.05 . Consistently with the evidence reported in [11] of wood chip production costs variation between countries, and depending on whether the raw material is obtained from the trees (USD 20092.87 - 7.80/GJ delivered to plant) or from residues (USD 20092.23 $6.38 / G J$ delivered to plant), we will assume that the price volatility of $2 \mathrm{G}$ biofuels is in between that of the rapeseed input and the electricity, and about 0.10 .

Once individual variances are estimated, the last piece of information needed to estimate the efficiency frontier is a cross-correlation matrix. To compute the gasolinediesel, $1 \mathrm{G}$ biofuels, and electricity cross-correlations we use the estimated HP-cycle of oil, rapeseed, sugar cane and electricity prices. Table 5 reports the cross-correlations among these alternatives. As expected, all correlations are positive and exhibit quantitatively meaningful differences. The higher correlation is between oil and electricity (0.51), well above the one between sugar cane and rapeseed (0.32). The correlation between 2G biofuels and the rest is not well established, but we will assume a value of 0.16 , on the basis of the similarities for the processes involved in the production of $1 \mathrm{G}$ and $2 \mathrm{G}$ biofuels and the fact that an internationally recognized market for 2G biofuels is not yet established. Following the discussion in Section 2, combining low-correlated alternatives would lower the risk of the fuel portfolio, even with respect to alternatives with similar and high individual risk values. This last aspect is extremely important for the proper design of a national energy policy.

\section{Results and discussion}

In this section we implement the mean-variance portfolio theory of Section 2 on the evidence discussed along Section 3. In so doing we calculate the energy efficiency 
frontier in the road transport sector. Because most of the information on costs has been taken from world energy statistics, we consider this frontier as a proxy for the global economy. Put differently, it will be interpreted as the frontier of a representative economy. Notice this is important in terms of the very relevant discussion on costs associated with the actual international trade flows in fuels. We illustrate our basic findings through a benchmark efficient frontier for fuel use under alternative scenarios. Then, we elaborate on different extensions related to changes in the price of $\mathrm{CO}_{2}$ emissions.

\subsection{The benchmark fuel efficiency frontier}

The fuel portfolio is composed by the set of weightings $\left(X_{1}, X_{2}, X_{3}, X_{4}, X_{5}, X_{6}\right)$, which add up to one and are subject to the technical restrictions discussed in Section 3.2. The average cost of the fuel portfolio is computed from equation (1), whereas the measure of risk is computed from expression (2) adapted for six components. Once the average cost and risk of a fuel portfolio are determined, the Efficient Frontier is computed from the set of all efficient portfolios. Recall that we have considered the alternatives: shortmedium term versus long term on the one hand and low (60USD/bbl) versus high (120USD/bbl) oil price on the other hand. Next, we focus on the implications from these alternatives.

Figure 3 depicts the estimated efficient frontier for the four scenarios that result from combining by pairs the alternatives above. As a reference mix for the frontier, we consider the one proposed by the European Commission [20]. This is the 'business-asusual' mix (the reference-BAU), which is about $93 \%$ of fossil fuels and $7 \%$ of $1 \mathrm{G}$ biofuels in the short-run (by 2011), and about $87 \%$ of fossil fuels and $13 \%$ of $1 \mathrm{G}$ biofuels in the long-run (by 2050). According to the European Commission as well, there is a proposal for a "low carbon road map target by 2050," which means 36\% of fossil fuels, 25\% biofuels (mostly of 2G) and 39\% of electricity. We also highlight the "MC (Minimum Costs)," the "MV (Minimum Variance)" and the "MC-MV (average between MC and MV)” efficiency portfolios that result from our mean-variance approach. These portfolios are compared with those reference scenarios proposed by the European Commission. Detailed results for the portfolios (the weights for each 
technology, as well as the average cost and the volatility) and for the alternative scenarios are shown in Table 6 (the short-run) and Table 7 (the long-run). Finally, a rough index of emissions reduction with respect to the reference portfolio is computed according to the data discussed along Section 3.2 (see Table 4).

For the short-run (Table 6), the reference-BAU mix is closer to efficiency when the price of oil is low. This finding is justified by the low costs associated with the reference mix under low oil prices. In such a case, the main drawback of the current mix is not the average cost (as far as one abstracts from emission costs), but the risk related to a high volatility of costs. This is because the current mix is very much concentrated on fossil fuels that exhibit not only a high volatility of costs but also, high correlations with the costs of the alternative technologies. Notice that the Minimum Variance (MV) portfolio puts on the minimum share, $70 \%$, fossil fuels, and diversifies as much as possible among the alternatives subject to the technological feasibility constraints. Thus, the low oil price short-run strategy implies moving towards efficiency with respect to the reference mix by reducing risk as much as possible. This reduction of risk also involves a reduction on emissions as byproduct, even though we are not yet internalizing into the analysis the emissions costs. Consequently, costs, risks and emissions go down when looking to the whole fuel mix while taking into account crosscorrelations. This finding is in sharp contrast with what is obtained from stand-alone comparisons, where the common conclusion is that it is not possible decreasing one dimension without increasing the other. Taking into account the entire fuel mix and the cross-correlations of the different fuel alternatives is crucial to achieve such a win-win solution.

Alternatively, and as already discussed throughout Section 3.2, when the price of oil is high sugar cane ethanol becomes very competitive. Moreover, following the same discussion there, if we keep the assumption of USD $0.2842 / \mathrm{kWh}$ for electricity, the cost of $1 \mathrm{G}$ ethanol is below that of electricity as well. Therefore, the high oil price portfolio is build upon the maximum shares of sugar cane ethanol and electricity that are feasible in the short-run, and the remaining (70\%) of fossil fuel. Beyond the inefficiency of the reference mix in the short-run due to high average costs associated to expensive oil, there is a problem of excess volatility. Indeed, the reference mix is far from the efficient 
frontier in the risk dimension. Similarly to the case with cheap oil, risk is substantially reduced through diversification as Panel B of Table 6 for the MV case illustrates.

In the long-run and particularly if the price of oil is high, the reference-BAU mix for 2050 is extremely far away from the efficient frontier. In such a setting inefficiency comes both from high average costs and substantial risk. Under low oil prices, both the MC portfolio and the average MC-MV portfolio give more weighting to electricity, and expand the role of biofuels. More precisely, the MC portfolio concentrates on electricity and $1 \mathrm{G}$ ethanol whereas the MC-MV portfolio diversifies between electricity and the $2 \mathrm{G}$ alternatives. These findings are substantially modified if the situation is one with high oil prices in the long-run, which is the more likely scenario according to the IEA. In that setting, electricity falls to an $18.4 \%$ share in the MC portfolio and a $28.3 \%$ share for the average MC-MV. In this latter case the share of biofuels is reduced to $22.2 \%$ for $2 \mathrm{G}$, and a relatively high (24.5\%) sugar cane ethanol share. Further, the feasibility constraint for the share of fossil fuels (25\%) becomes binding. Electricity by itself and because of its complementarity with biofuels becomes crucial to reduce risks in the long run. This circumstance is clearly illustrated through inspection of the MV portfolio under any price scenario.

It is also worth noting that the fuel mix targeted by the 'low carbon road map scenario' is much closer to the efficiency frontier. Furthermore, under the low oil price setting, the low carbon scenario is very similar to the mean MC-MV efficient portfolio. For the high oil price scenario, however, some notable improvements in both the mean and the variance dimensions could be achieved face to face the average MC-MV mix.

The key finding which is robust for all specifications is that diversification through biofuels, notably $2 \mathrm{G}$ biofuels, and electricity, drives reductions of risk that are quantitatively important. In the case of biofuels this is because they have a low correlation with fossil fuels and within them. In the case of electricity it is because of its low volatility as far as this fuel input is a mix in itself. Another important result is that this type of diversification meaningfully generates the maximum reduction in $\mathrm{CO}_{2}$ emissions with respect to the reference mix. For instance, the estimated reduction in emissions in the short-run for the MV portfolio is $12.1 \%$, even though the feasibility constraint imposes a share of fossil fuels of 70\%. Long-run emission reductions go up to $34.5 \%$. 


\subsection{Emission permits cost}

Previous results have been obtained under the assumption of a zero cost of $\mathrm{CO}_{2}$ emissions. The cost of emissions mostly affects the costs of fossil fuels, notably in the short run. It also affects the electricity price if fossil primary energy is at work in the long run for generating electric power. Therefore, alternative regulatory schemes on emissions leave the penetration of different technologies particularly open in the longrun. For the sake of clarity we solely focus here on foreseen changes in the price of $\mathrm{CO}_{2}$. Any further changes in electricity price beyond the previous assumptions for the short-run and the lung-run are beyond the scope of this paper.

Through use of the evidence reported in Table 4 on emissions per kilometer by the different technologies we can minimally assess the role of climate change policies. We assume either a low price of emissions, USD 20/ton $\mathrm{CO}_{2}$ (variant 1), similar to current levels (roughly above USD 10/ton $\mathrm{CO}_{2}$ along these days), versus a USD 80/ton $\mathrm{CO}_{2}$ (variant 2), which is around the level the IEA and other environmental organizations foresee as likely to occur in the medium-long run.

For these different environments the variance-covariance matrix is maintained across experiments, and we estimate the corresponding efficient frontiers (not shown in the paper). Tables 8 and 9 report the main results, for the benchmark and the two variants, under the four scenarios considered in the previous section (short vs. long-run; low vs. high oil prices). To facilitate the exposition we only report results for the average MCMV portfolio.

In the short-run and under a low oil price scenario (Table 8) the composition of the MCMV portfolio barely changes with respect to the benchmark once emission costs are incorporated into the analysis. Indeed, under a low price of oil, emissions costs have to be well above $80 \mathrm{USD} /$ ton $\mathrm{CO}_{2}$ in order to significantly affect the share of fossil fuels in the efficient mix. The penetration of electricity is at its maximum share (10\%) in all of the cases. Therefore, increasing $\mathrm{CO}_{2}$ emissions cost reduces the share of fossil fuels in favor of biofuels. This pattern gives rise to some emission reductions as well. In the short-run when the oil price is high and with a high cost linked to $\mathrm{CO}_{2}$ emissions, it occurs that fossil fuels are led to its minimum share in the mix (70\%). These 
alternatives give rise to the minimum $\mathrm{CO}_{2}$ emissions at the same time. However, we must emphasize that improvements with respect to the benchmark setting are not so important. In fact, portfolios are quite similar in all of the cases. The reason is that, given technical restrictions in the short-run, high oil prices seem to be enough to guarantee low emissions at the same time that a low risk scenario is achieved. This finding suggests that market-based price policies could achieve important risk and emissions reductions without much change in the average cost of the fuel portfolio. The key issue is on incentives to diversify among low correlated alternatives which in addition results in less polluting alternatives.

For the long-run and in regard to the MC-MV portfolio, the share of fossil fuels is always on the lower bound (25\%). When the oil price is low we find that electricity takes the lead, reaching almost $50 \%$ of the mix, while biofuels, particularly $2 \mathrm{G}$, represent the remaining 25\% of the mix. Increases in $\mathrm{CO}_{2}$ emissions cost provoke small changes in the mix, although increasing the share of biofuels and reducing that of electricity. On the other hand, when the oil price is high in the long-run (and electricity prices are also high), this is the case where the higher share from biofuels in the fuel mix is obtained. Moreover, the switch in the mix from electricity to biofuels rises as the $\mathrm{CO}_{2}$ cost increases. Thus, for zero cost of emissions, we have already shown that the biofuels share was about $45 \%$ while that of electricity was about 30\%. However, when $\mathrm{CO}_{2}$ costs increase up to USD 80/ton, the electricity share goes to zero and biofuels represents about $75 \%$ instead, which results in the more favorable scenario for emissions abatement. Indeed, this latter configuration reflects the high correlation assumed between oil and electricity prices.

\section{Conclusions}

The main goal of this paper is to evaluate the impacts of fuel price volatility for the diversification of aggregate risks in the road transport sector. Combining the average fuel costs and their volatilities and cross-correlations, Mean-Variance Portfolio Theory is implemented under different scenarios. The main finding is that the current fuel portfolio is very inefficient in terms of average cost and a lack of diversification. This is particularly so in a long-run high oil price setting. Also, almost any possible scenario 
indicates that in order to reduce the overall risk, there must be a shift toward fuel portfolios that include a significant share of biofuels and electricity, the latter depending upon the uncertain evolution of the electricity technology for the road transport.

Our main result refers to the complementarities between electricity and second generation biofuels that occur in the long-run, whereas such complementarities are only modest and with first generation biofuels (domestic and imported) in the short-run. Under a high oil price scenario, a strong substitution of fossil fuels by electricity and biofuels is found to be in the efficient frontier of the fuel portfolio in the long-run, while the weight of fossil fuels stays about $70 \%$ if oil prices are assumed to stay low in the short-run. These findings give an important role to biofuels and their complementarities with fossil fuels in the short-run and with electricity in the long-run, and confirm biofuels as a key element in a path designed to achieve the main energy policy goals in the transport sector in the short- and in the long-run.

The results of this empirical investigation serve to highlight the important role played by biofuels in reducing volatility and systematic risk in a fuel mix, due to their correlation structure with other fuel technologies. Clearly, correlation between gasoline and diesel price is close to one, whereas first with second generation biofuels or any of these with electricity if the source for electric power is mostly renewable or even natural gas they may represent low correlated combinations. Moreover, $\mathrm{CO}_{2}$ emission reductions associated with such an efficient diversification can diminish to almost 58\% from a $100 \%$ fossil fuels scenario. Therefore, the complementarities between fossil energies, biofuels, and electricity, seem a relevant factor for the energy policy in the transport sector in order to reduce dependence, increase diversification and lower emissions.

As a final caveat, we have to emphasize that our analysis misses the interdependence between economic agents, which would require an understanding of the underlying market structure. In contrast to mean-variance theory, equilibrium theories of energy use [36-37] or fuel use in the transport sector [51] under aggregate uncertainty deal explicitly with forward looking behavior. We aim at the evidence and findings in this paper to contribute to the proper specification of equilibrium environments for fuel use. 


\section{References}

[1] IEA. Key World Energy Statistics 2011, 2010, 2009, 2008, 2007. IEA; 2007-2011.

[2] IEA. Energy Technology Perspectives 2010. IEA; 2010.

[3] Commission Green Paper: a European Strategy for Sustainable, Competitive and Secure Energy. European Commission; 2006.

[4] Moselle, B. Renewable generation and security of supply, Harnessing Renewable Energy in Electricity Power Systems, Ch. 4. Earthscan; 2010.

[5] Markowitz HM. Portfolio selection. Journal of Finance 1952; 7: 77-91.

[6] Merton RC. An analytic derivation of the efficient portfolio frontier. The Journal of Finance and Quantitative Analysis 1972; 7: 1851-1872.

[7] Awerbuch S, Berger M. Applying portfolio theory to UE electricity planning and policy-making, IEA/EET, Paris (2003). Available from http://www.awerbuch.com/shimonpages/shimondocs/iea-portfolio.pdf

[8] Roques FA, Newbery DM, Nuttall WJ. Fuel mix diversification incentives in liberalized electricity markets: A Mean-Variance Portfolio theory approach. Energy Economics 2008; 30: 1831-1849.

[9] Marrero GA, Ramos-Real FJ. Electricity generation cost in isolated system: the complementarities of natural gas and renewables in the Canary Islands. Sustainable and Renewable Energy Reviews 2010; 14: 2808-2818.

[10] Arnesano M, Carlucci AP, Laforgia D. Extension of portfolio theory application to energy planning problem. The Italian case. Energy 2011; doi: 10.1016/j.energy.2011.06.053.

[11] IEA. Bioenergy - A sustainable and reliable energy source. IEA Bioenergy; 2009. [12] IEA. Sustainable Production of Second-Generation Biofuels. IEA; 2010.

[13] Schade B, Wiesenthal T. Biofuels: A model based assessment under uncertainty applying the Monte Carlo method. Journal of Policy Modeling 2011; 33: 92-126. 
[14] Gül T, Kypreos S, Turton H, Barreto L. An energy-economic scenario analysis of alternative fuels for personal transport using the Global Multi-regional MARKAL model (GMM). Energy 2009; 34: 1423-37.

[15] Wright L, Fulton L. Climate Change Mitigation and Transport in Developing Nations. Transport Reviews 2005; 25: 691-717.

[16] Creutziga F, Heb D. Climate change mitigation and co-benefits of feasible transport demand policies in Beijing. Transportation Research Part D: Transport and Environment 2009; 14: 120-131.

[17] Poudenx. P. The effect of transportation policies on energy consumption and greenhouse gas emission from urban passenger transportation. Transportation Research Part A 2008; 42: 901-909.

[18] Juul N, Meibom P. Optimal configuration of an integrated power and transport system. Energy 2011; 36: 3523-30.

[19] Ajanovic A, Haas R. Economic challenges for the future relevance of biofuels in transport in EU countries. Energy 2010; 35: 3340-48.

[20] EC. A roadmap for moving to a competitive low carbon economy in 2050. 2011. See also: http://eur- lex.europa.eu/LexUriServ/LexUriServ.do?uri =SEC:2011:0288:FIN:EN:PDF.

[21] Böhringer C, Löschel A, Moslener U, Rutherford TF. EU climate policy up to 2020: An economic impact assessment. Energy Economics 2009; 31: S295-S305.

[22] Marrero G. Greenhouse gases emissions, growth and the energy mix in Europe, Energy Economics 2010; 32: 1356-1363.

[23] Li S. Reduction emissions from transport sector - EU action against climate change. Modern Applied Science 2009; 3: 56-62.

[24] Van-Zijl T. Risk decomposition: variance or standard deviation - a reexamination and extension. Journal of Financial and Quantitative Analysis 1987; 22: 237-247.

[25] Fama EF, French KR. The cross-section of expected stock returns. Journal of Financial Economics 1993; 33: 3-56. 
[26] Awerbuch S. Portfolio-based electricity generation planning: policy implications for renewables and energy security. Mitigation and Adaptation Strategies for Global Change 2006; 11: 693-710.

[27] Wiser R, Bachrach D, Bolinger M, Golove W. Comparing the risk profiles of renewable and natural gas-fired electricity contracts. Renewable and Sustainable Energy Review 2004; 8: 335-336.

[28] IEA. Bioenergy, land use change and climate change mitigation. IEA Bioenergy; 2011.

[29] IPCC. Fourth Assessment Report: Climate Change 2007 (AR4); 2008.

[30] Guerrero-Lemus, R, Martínez-Duart, JM. Updated hydrogen production costs and parities for conventional and renewable technologies. International Journal of Hydrogen Energy 2010; 35: 3929-3936.

[31] Foust, TD. Advanced drop-in biofuels. Presented at Rethinking Energy and Climate Strategies for Transportation - Thirteenth Biennial Conference on Transportation and Energy, Pacific Grove, CA, September 1; 2011.

[32] International Energy Outlook 2006. Office of Integrated Analysis and Forecasting, U.S. Department of Energy, EIA-DOE, Washington, DC; 2006.

[33] IEA. World Energy Outlook 2008, OECD/IEA Paris, France; 2008.

[34] Energy Information Administration. Annual Energy Outlook 2011. US Department of Energy; 2011.

[35] Kilian, L. The economic effects of energy price shocks. Journal of Economic Literature 2008; 46: 871-909.

[36] Atkeson, A, Kehoe, PJ. Models of energy use: putty-putty versus putty-clay. American Economic Review 1999; 89: 1028-1043.

[37] Díaz, A, Puch, LA, Guilló, MD. Costly capital reallocation and energy use. Review of Economic Dynamics 2004; 7: 494-518.

[38] Fuel Economy Guide. Model Year 2012. US Department of Energy and US Environmental Protection Agency; 2011. 
[39] Biodiesel handling and use guide, $4^{\text {th }}$ edition. National Renewable Energy Laboratory. US Department of Energy; 2009.

[40] European Central Bank. Euro exchange rates. Available from:

http://www.ecb.int/stats/exchange/eurofxref/html/eurofxref-graph-usd.en.html

[41] US Department of Energy. Energy Information Administration; several years.

[42] OECD. Biofuel support policies: An economic assessment. OECD, Paris, France; 2008.

[43] CONCAWE (JEC). Well-to-Wheels analysis of future automotive fuels and powertrains in the European context. Well-to-wheels report, Version 2c.: JRC, EUCAR, CONCAWE (JEC). Brussels, Belgium; 2007.

[44] OECD. Economic assessment of biofuel support policies. OECD, Paris, France; 2008.

[45] DEFRA. Estimating the cost-effectiveness of biofuels. Department for Environment, Food and Rural Affairs (DEFRA), London, UK; 2008.

[46] Department for Transport. International resource costs of biodiesel and bioethanol. Department for Transport, London, UK; 2006.

[47] Energy Charter Secretariat. Driving without petroleum? A comparative guide to biofuels, gas-to-liquids and coal-to-liquids as fuels for transportation. Energy Charter Secretariat, Brussels, Belgium; 2007.

[48] CONCAWE (JEC). Well-to-wheels analysis of future automotive fuels and powertrains in the European context. Well-to-tank report version 3.0 November 2009. WTT App.2-Description and detailed energy and GHG balance of individual pathways. JRC, EUCAR, CONCAWE (JEC). Brussels, Belgium; 2008.

[49] Environmental Protection Agency (USA).

http://www.epa.gov/oms/climate/420f05001.htm\#carbon

[50] Hodrick, RJ, Prescott, EC. Postwar U.S. business cycles: an empirical investigation. Journal of Money, Credit and Banking 1997; 29: 1-16.

[51] Ríos-Rull, JV and Rodríguez-López, J. Cars, Mimeo; 2011. 


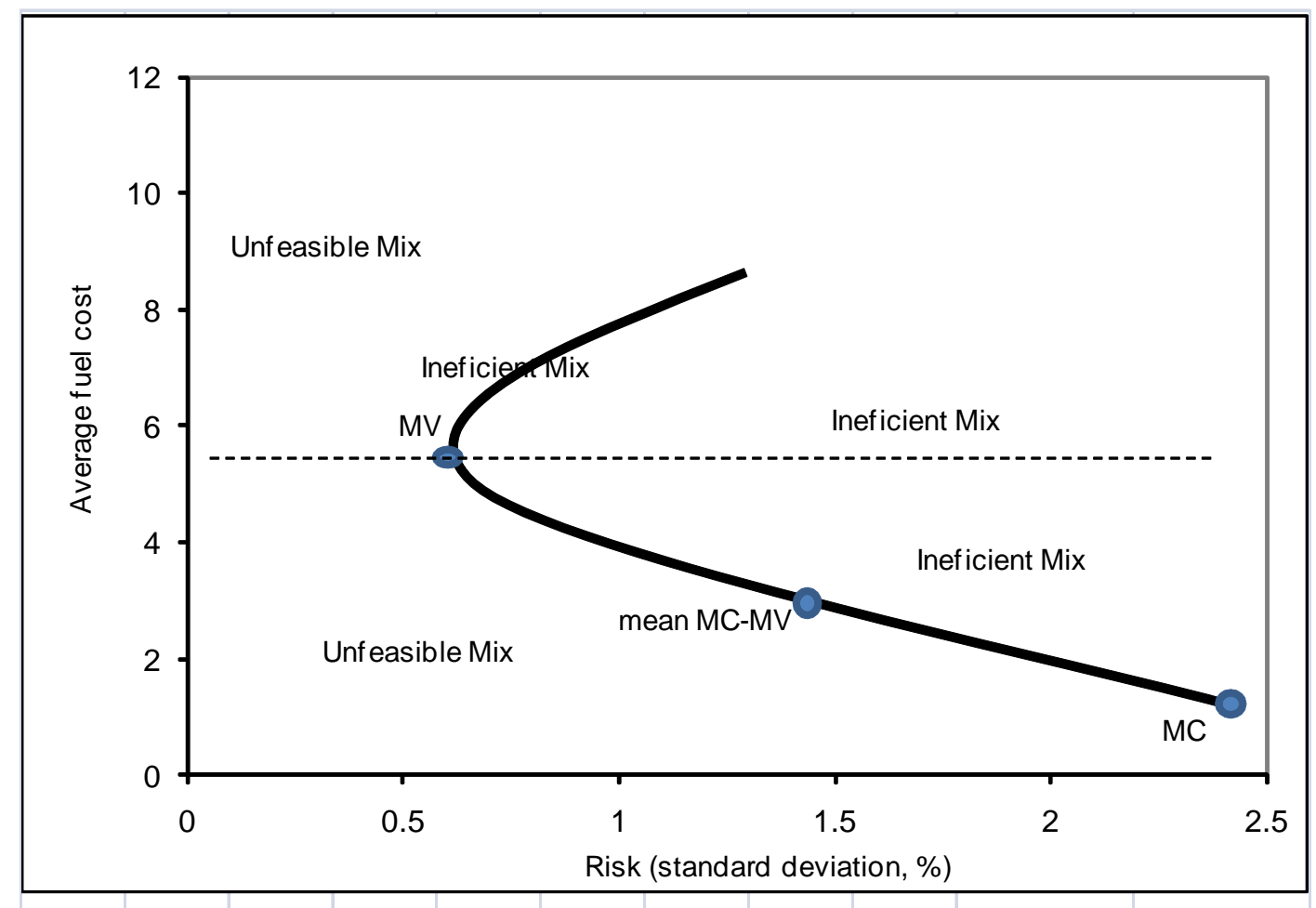

Figure 1. A hypothetical efficient fuel portfolio frontier. MV: Minimum Variance (risk) portfolio in the frontier; MC: Minimum Cost portfolio; the mean MC-MV mix refers to an efficient portfolio where its cost is the average between that of MC and MV.

\begin{tabular}{|l|l|l|l|}
\cline { 3 - 4 } \multicolumn{2}{c|}{} & $\begin{array}{l}\text { USD } \\
\text { (USD } 2009 \\
\text { (USD/bbl }\end{array}$ & $\begin{array}{l}\text { USD }_{2009} 120 / \mathrm{bbl} \\
\left(\text { USD }_{2009} / \text { lge }\right)\end{array}$ \\
\hline \multirow{4}{*}{ Short-run } & Cellulosic ethanol & 0.91128 & 1.08886 \\
\cline { 2 - 4 } & BtL & 0.83993 & 1.07459 \\
\cline { 2 - 4 } & Sugar cane ethanol & 0.45305 & 0.54674 \\
\cline { 2 - 4 } & Corn ethanol & 0.62948 & 0.83632 \\
\cline { 2 - 4 } & Rapeseed biodiesel & 0.82076 & 1.06364 \\
\hline \multirow{5}{*}{ Long-run } & Cellulosic ethanol & 0.61939 & 0.72159 \\
\cline { 2 - 4 } & BtL & 0.57485 & 0.73225 \\
\cline { 2 - 4 } & Sugar cane ethanol & 0.40706 & 0.48605 \\
\cline { 2 - 4 } & Corn ethanol & 0.48995 & 0.70241 \\
\cline { 2 - 4 } & Rapeseed biodiesel & 0.72591 & 0.95798 \\
\hline \multirow{5}{*}{} & Gasoline & 0.47227 & 0.84516 \\
\cline { 2 - 4 } & Diesel & 0.48952 & \\
\cline { 2 - 4 } & & & \\
\hline
\end{tabular}

Table 1. Comparison of biofuel cost estimations in the short and long-run in USD2009 per liter of gasoline equivalent (lge). 


\begin{tabular}{|l|l|l|l|}
\hline Type & Model & Combined km/l & $\begin{array}{l}\text { Engine } \\
\text { size/cilinders }\end{array}$ \\
\hline Hybrid & Toyota Prius & 21 & $1.8 / 4$ \\
\hline Ethanol Flexible & Chevrolet Malibu & $8($ E85)/11(gas) & $2.4 / 4$ \\
\hline Electric battery* & Nissan Leaf & 43 & $80 \mathrm{~kW}$ \\
\hline Diesel & Volkswagen Golf & 15 & $2.0 / 4$ \\
\hline
\end{tabular}

(*) EPA: $1 \mathrm{l}$ of gasoline $=8.903 \mathrm{kWh}$.

Table 2. Fuel and electricity consumption characteristics of the most efficient midsize car models in terms of kilometers per liter or equivalent.

\begin{tabular}{|c|c|c|c|c|c|}
\hline & & model & \begin{tabular}{|l|}
$\mathrm{USD}_{2009}$ \\
$60 / \mathrm{bbl}$ \\
$\left(\mathrm{USD}_{2009} / \mathrm{km}\right)$ \\
\end{tabular} & \begin{tabular}{|l|}
$\mathrm{USD}_{2009}$ \\
$120 / \mathrm{bbl}$ \\
$\left(\mathrm{USD}_{2009} / \mathrm{km}\right)$ \\
\end{tabular} & fuel \\
\hline \multirow[t]{2}{*}{$\begin{array}{c}\text { At } \\
\text { present }\end{array}$} & $\begin{array}{l}\text { Cellulosic ethanol } \\
\text { BtL } \\
\text { Sugar cane ethanol } \\
\text { Corn ethanol } \\
\text { Rapeseed biodiesel }\end{array}$ & $\begin{array}{l}\text { Chevrolet Malibu } \\
\text { Volkswagen Golf } \\
\text { Chevrolet Malibu } \\
\text { Chevrolet Malibu } \\
\text { Volkswagen Golf }\end{array}$ & $\begin{array}{l}0.08196 \\
0.07554 \\
0.04075 \\
0.05661 \\
0.07382\end{array}$ & $\begin{array}{l}0.09793 \\
0.09665 \\
0.04917 \\
0.07522 \\
0.09566\end{array}$ & $\begin{array}{l}\text { E85 } \\
\text { B5 } \\
\text { E85 } \\
\text { E85 } \\
\text { B5 }\end{array}$ \\
\hline & Electricity & Nissan Leaf & 0.02391(US) & 0.05883(IT) & \\
\hline \multirow[t]{3}{*}{ Long-run } & $\begin{array}{l}\text { Cellulosic ethanol } \\
\text { BtL } \\
\text { Sugar cane ethanol } \\
\text { Corn ethanol } \\
\text { Rapeseed biodiesel }\end{array}$ & \begin{tabular}{|l} 
Chevrolet Malibu \\
Volkswagen Golf \\
Chevrolet Malibu \\
Volkswagen Golf \\
Chevrolet Malibu \\
\end{tabular} & \begin{tabular}{|l|}
0.05571 \\
0.05170 \\
0.03661 \\
0.04406 \\
0.06529 \\
\end{tabular} & \begin{tabular}{|l|}
0.06490 \\
0.06586 \\
0.04371 \\
0.06317 \\
0.08616 \\
\end{tabular} & \begin{tabular}{|l} 
E85 \\
B5 \\
E85 \\
E85 \\
B5 \\
\end{tabular} \\
\hline & Electricity (high coal price) & Nissan Leaf & 0.02570 (US) & $0.06323(\mathrm{IT})$ & \\
\hline & $\begin{array}{l}\text { Gasoline } \\
\text { Diesel }\end{array}$ & $\begin{array}{l}\text { Chevrolet Malibu } \\
\text { Volkswagen Golf }\end{array}$ & $\begin{array}{l}0.04293 \\
0.03263\end{array}$ & $\begin{array}{l}0.07683 \\
0.05490\end{array}$ & $\begin{array}{l}100 \% \\
100 \%\end{array}$ \\
\hline
\end{tabular}

US: United States of America; IT: Italy.

Table 3.- Comparison of biofuel cost and electricity price estimations in the short and long-run in USD2009 per kilometer. 


\begin{tabular}{|c|c|c|c|c|}
\hline & $\mathrm{g} \mathrm{CO}_{2} / \mathrm{MJ}$ & $\mathrm{MJ} / \mathrm{l}$ & Model/energy carrier & $\mathrm{g} \mathrm{CO}_{2} / \mathrm{km}$ \\
\hline Cellulosic ethanol* & 7.38 & 24.91 & Chevrolet Malibu/E85 & 22.98 \\
\hline Sugar cane ethanol* & 25.51 & $24.91^{-}$ & Chevrolet Malibu/E85 & 79.45 \\
\hline Rapeseed biodiesel* & 40.03 & $38.47^{-1}$ & Volkswagen Golf/B5 & 102.65 \\
\hline $\mathrm{BtL}^{*}$ & 6.90 & $38.47^{-}$ & Volkswagen Golf/B5 & 17.69 \\
\hline Gasoline* & 67.12 & 34.63 & Chevrolet Malibu/gasoline & 211.31 \\
\hline Gasoline* & 67.12 & 34.63 & Toyota Prius/gasoline & 110.66 \\
\hline Diesel* & 69.02 & 38.66 & Volkswagen Golf/diesel & 177.88 \\
\hline World electricity from petroleum** & 180.90 & $32.05^{\circ}$ & Nissan Leaf/electricity & 134.83 \\
\hline World electricity from coal** & 249.51 & $32.05^{\circ}$ & Nissan Leaf/electricity & 185.96 \\
\hline World electricity from natural gas** & 108.64 & $32.05^{\circ}$ & Nissan Leaf/electricity & 80.97 \\
\hline World electricity** & 139.54 & 32.05 & Nissan Leaf/electricity & 104.00 \\
\hline
\end{tabular}

$\left({ }^{*}\right)$ EIA: $1 \mathrm{l}$ of gasoline $=34.63 \mathrm{MJ} ; 1 \mathrm{l}$ of ethanol $=23.20 \mathrm{MJ} ; 1 \mathrm{l}$ of diesel $=38.66 \mathrm{MJ} ; 1 \mathrm{l}$ of biodiesel $=34.79 \mathrm{MJ}$.

$(* *) 1 \mathrm{l}$ of gasoline $=8.903 \mathrm{kWh}(\mathrm{EPA}) ;$ IEA: $1 \mathrm{MJ}=0.2778 \mathrm{kWh}($ IEA $)$.

Table 4.- CO2 emissions from different fuels and electricity per MJ, and CO2 emissions per kilometer for the midsize cars considered above.
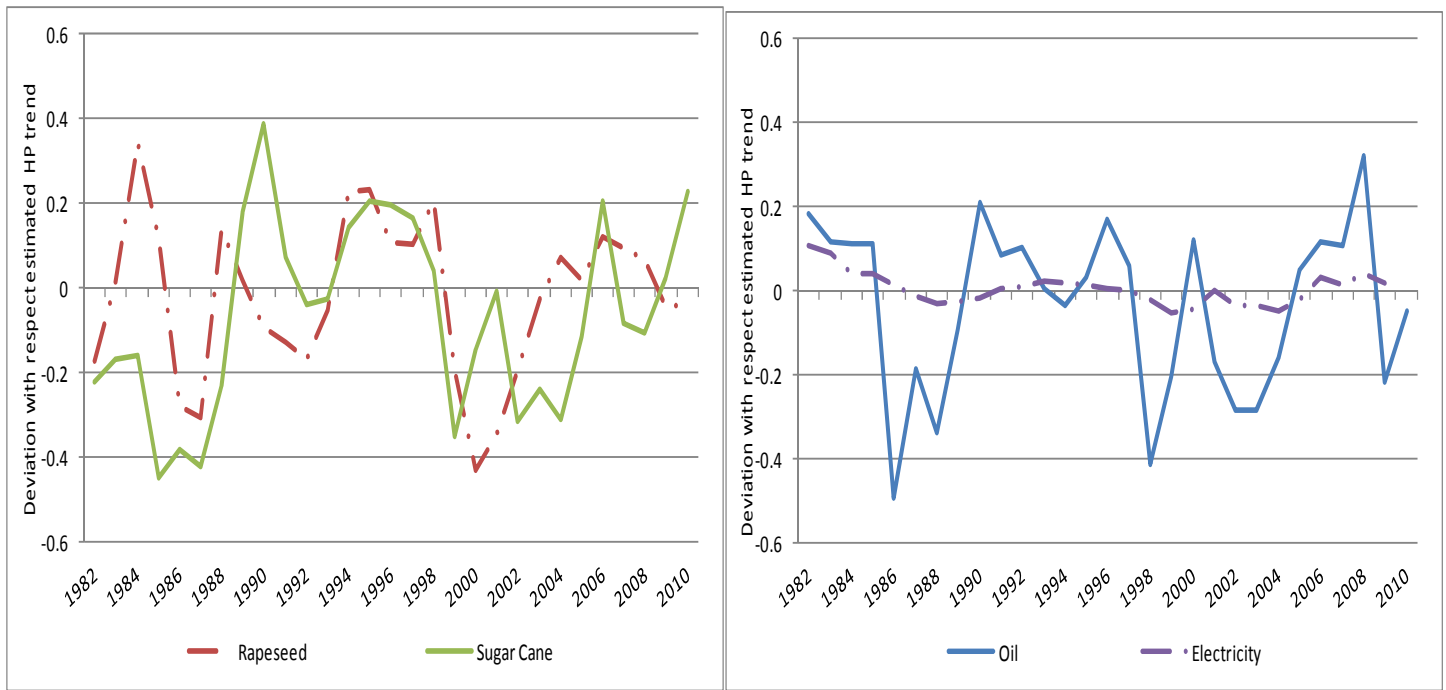

Figure 2.- Estimated HP-cycle of oil, electricity, rapeseed and sugar cane prices. Units: (log) deviations with respect to the estimated Hodrick and Prescott (HP) trend. Units: deviations with respect to the estimated Hodrick and Prescott (HP) trend. 


\begin{tabular}{|c|c|c|c|c|}
\hline & Oil & Rapeseed & Sugar cane & Electricity \\
\hline Oil & 1.00 & 0.18 & 0.38 & 0.51 \\
\hline Rapeseed & 0.18 & 1.00 & 0.33 & \\
\hline Sugar cane & 0.38 & 0.33 & & \\
\hline Electricity & 0.51 & & & \\
\hline
\end{tabular}

Table 5: Cross - Correlations among alternative fuel technologies (own calculations).
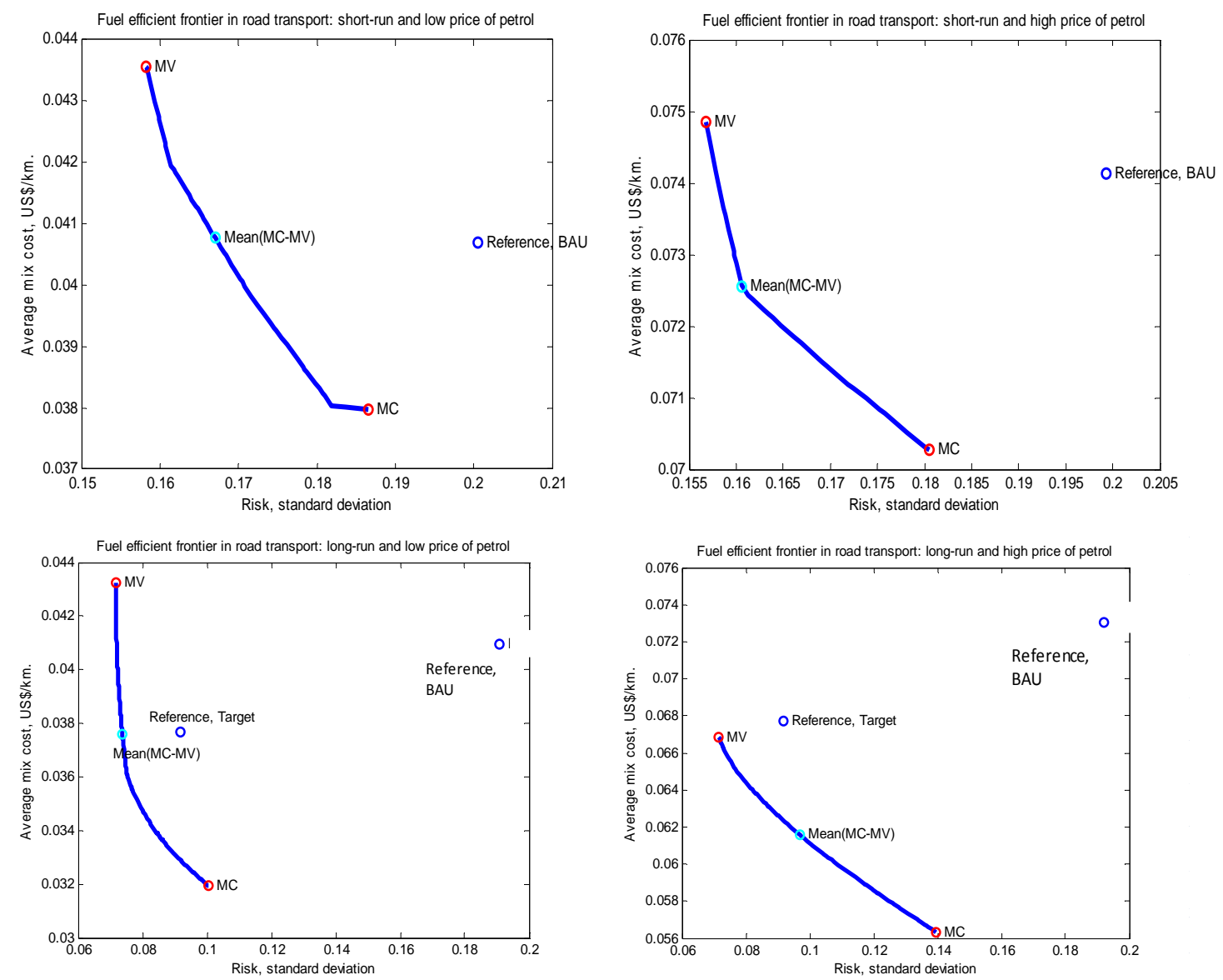

Figure 3.- Estimated Fuel Efficient Frontier for the road transport in the short-run (top panel) and long-run (bottom panel), under low (left) and high (right) oil prices. 


\begin{tabular}{|c|c|c|c|c|}
\hline \multicolumn{5}{|c|}{ A) low petrol price: 60 US\$\$/barrel } \\
\hline & $\begin{array}{c}\text { Reference, } \\
\text { BAU }\end{array}$ & MC & MV & MC-MV \\
\hline Cost,US\$/km & 0.0407 & 0.0380 & 0.0436 & 0.0408 \\
\hline Risk & 0.2005 & 0.1866 & 0.1583 & 0.1671 \\
\hline Gaso-diesel, $\mathrm{X}_{1}$ & 93.0 & 84.8 & 70.0 & 72.8 \\
\hline Sugar cane ethanol(1g), $X_{2}$ & 3.5 & 5.2 & 5.1 & 10.0 \\
\hline Rapeseed biodiesel(1g), $X_{3}$ & 3.5 & 0.0 & 4.9 & 0.0 \\
\hline Cellulosic ethanol(2g), $\mathrm{X}_{4}$ & 0.0 & 0.0 & 5.0 & 2.2 \\
\hline Blt biodiesel(2g), $X_{5}$ & 0.0 & 0.0 & 5.0 & 5.0 \\
\hline Electricity, $\mathrm{X}_{6}$ & 0.0 & 10.0 & 10.0 & 10.0 \\
\hline CO2, index $=100$ if $100 \%$ fosil & 96.0 & 94.0 & 83.9 & 87.6 \\
\hline \multicolumn{5}{|c|}{ B) high petrol price: 120 US\$\$/barrel } \\
\hline & $\begin{array}{c}\text { Reference, } \\
\text { BAU }\end{array}$ & MC & MV & MC-MV \\
\hline Cost,US\$/km & 0.0741 & 0.0703 & 0.0748 & 0.0726 \\
\hline Risk & 0.1992 & 0.1806 & 0.1568 & 0.1606 \\
\hline Gaso-diesel, $\mathrm{X}_{1}$ & 93.0 & 79.8 & 70.0 & 70.0 \\
\hline Sugar cane ethanol(1g), $x_{2}$ & 3.5 & 10.0 & 5.0 & 9.9 \\
\hline Rapeseed biodiesel(1g), $X_{3}$ & 3.5 & 0.0 & 5.0 & 0.1 \\
\hline Cellulosic ethanol(2g), $\mathrm{X}_{4}$ & 0.0 & 0.0 & 5.0 & 5.0 \\
\hline Blt biodiesel(2g), $X_{5}$ & 0.0 & 0.2 & 5.0 & 5.0 \\
\hline Electricity, $\mathrm{x}_{6}$ & 0.0 & 10.0 & 10.0 & 10.0 \\
\hline CO2, index $=100$ if $100 \%$ fosil & 96.0 & 92.1 & 83.9 & 85.8 \\
\hline
\end{tabular}

Notes: Limits to the individual shares are: $X_{1}$ between $70-100 ; X_{2}$ and $X_{6}$ between $0-10$;

$X_{3}, X_{4}$ and $X_{5}$ between $0-5$

MC: minimum cost mix in the frontier

MV: minimum variance mix in the frontier

Mean(MC-MV): mix in the frontier with averaged costs of $M C$ and MV

Reference BAU mix: $X_{1}=93 ; X_{3}=X_{2}=3.5 ; X_{4}=X_{5}=X_{6}=0$

Table 6.- Short-run portfolios and alternative scenarios (BAU, MC, MV and MC-MV) for USD 60/bbl and USD 120/bbl. 


\begin{tabular}{|c|c|c|c|c|c|}
\hline \multicolumn{6}{|c|}{ A) low petrol price: 60 US\$/barrel } \\
\hline & $\begin{array}{c}\text { Reference, } \\
\text { BAU }\end{array}$ & $\begin{array}{c}\text { Reference, } \\
\text { target EC } \\
2050\end{array}$ & $\mathrm{MC}$ & MV & MC-MV \\
\hline Cost,US\$/km & 0.0409 & 0.0377 & 0.0319 & 0.0433 & 0.0376 \\
\hline Risk & 0.1909 & 0.0919 & 0.1006 & 0.0716 & 0.07375 \\
\hline Gaso-diesel, $\mathrm{X}_{1}$ & 87.0 & 36.0 & 25.0 & 25.0 & 25.0 \\
\hline Sugar cane ethanol(1g), $X_{2}$ & 6.5 & 0.0 & 24.6 & 0.0 & 0.0 \\
\hline Rapeseed biodiesel(1g), $X_{3}$ & 6.5 & 0.0 & 0.0 & 1.3 & 0.0 \\
\hline Cellulosic ethanol(2g), $\mathrm{X}_{4}$ & 0.0 & 13.0 & 0.0 & 26.5 & 16.5 \\
\hline Blt biodiesel(2g), $\mathrm{X}_{5}$ & 0.0 & 12.0 & 0.4 & 21.8 & 13.4 \\
\hline Electricity, $\mathrm{X}_{6}$ & 0.0 & 39.0 & 50.0 & 25.5 & 45.1 \\
\hline CO2, index $=100$ if $100 \%$ fosil & 92.5 & 68.6 & 70.6 & 58.0 & 63.0 \\
\hline \multicolumn{6}{|c|}{ B) high petrol price: 120 US\$/barrel } \\
\hline & $\begin{array}{c}\text { Reference, } \\
\text { BAU }\end{array}$ & $\begin{array}{c}\text { Reference, } \\
\text { target EC } \\
2050\end{array}$ & $\mathrm{MC}$ & $\mathrm{MV}$ & MC-MV \\
\hline Cost,US\$/km & 0.0731 & 0.0677 & 0.0563 & 0.0669 & 0.0616 \\
\hline Risk & 0.1921 & 0.0917 & 0.1395 & 0.0716 & 0.09679 \\
\hline Gaso-diesel, $\mathbf{X}_{1}$ & 87.0 & 36.0 & 25.0 & 25.0 & 25.0 \\
\hline Sugar cane ethanol(1g), $X_{2}$ & 6.5 & 0.0 & 50.0 & 0.3 & 24.5 \\
\hline Rapeseed biodiesel(1g), $X_{3}$ & 6.5 & 0.0 & 0.0 & 0.0 & 0.0 \\
\hline Cellulosic ethanol(2g), $\mathrm{X}_{4}$ & 0.0 & 13.0 & 6.6 & 26.5 & 18.8 \\
\hline Blt biodiesel(2g), $X_{5}$ & 0.0 & 12.0 & 0.0 & 18.6 & 3.4 \\
\hline Electricity, $\mathrm{X}_{6}$ & 0.0 & 39.0 & 18.4 & 29.6 & 28.3 \\
\hline $\mathrm{CO} 2$, index $=100$ if $100 \%$ fosil & 92.5 & 68.6 & 69.4 & 59.3 & 65.2 \\
\hline \multicolumn{6}{|c|}{ Notes: Limits to the individual shares are: $X_{1}$ between $25-100 ; X_{2}$ and $X_{4}$ between $0-50 ; X_{3}$ and $X_{5}$ between $0-25$} \\
\hline \multicolumn{6}{|l|}{$\mathrm{X}_{6}$ is between $0-75$} \\
\hline \multicolumn{6}{|c|}{ MC: minimum cost mix in the frontier } \\
\hline \multicolumn{6}{|c|}{ MV: minimum variance mix in the frontier } \\
\hline \multicolumn{6}{|c|}{ Mean(MC-MV): mix in the frontier with averaged costs of MC and MV } \\
\hline \multicolumn{6}{|c|}{ Reference (BAU) mix: $X_{1}=87 ; X_{3}=X_{2}=6.5 ; X_{4}=X_{5}=X_{6}=0$} \\
\hline Target mix: $X_{1}=36 ; X_{2}=0 ; X_{3}=0, x$ & $=12, X_{6}=39$ & & & & \\
\hline
\end{tabular}

Table 7.- Long-run portfolios and alternative scenarios (BAU, MC, MV and MC-MV) for USD 60/bbl and USD 120/bbl. 


\begin{tabular}{|c|c|c|c|c|c|c|}
\hline & \multicolumn{6}{|c|}{ Short-run scenario (MC-MV efficiency mix) } \\
\hline & \multicolumn{3}{|c|}{ Low petroleum price } & \multicolumn{3}{|c|}{ High petroleum price } \\
\hline & $\begin{array}{c}\text { Benchmark } \\
\text { setting: } \\
\text { P CO2 }=0\end{array}$ & $\begin{array}{l}\text { Variant 1: } \\
\text { P CO2=20 }\end{array}$ & $\begin{array}{l}\text { Variant 2: } \\
\text { P CO2=80 }\end{array}$ & $\begin{array}{c}\text { Benchmark } \\
\text { setting: } \\
\text { P CO2=0 }\end{array}$ & $\begin{array}{l}\text { Variant 1: } \\
\text { P CO2=20 }\end{array}$ & $\begin{array}{l}\text { Variant 2: } \\
\text { P CO2=80 }\end{array}$ \\
\hline Cost,US\$/km & 0.0408 & 0.0450 & 0.0581 & 0.0726 & 0.0767 & 0.0891 \\
\hline Risk & 0.1671 & 0.1667 & 0.1618 & 0.1606 & 0.1613 & 0.1612 \\
\hline Gaso-diesel, $\mathbf{X}_{1}$ & 72.8 & 72.7 & 70.4 & 70.0 & 70.0 & 70.0 \\
\hline Sugar cane ethanol(1g), $x_{2}$ & 10.0 & 10.0 & 10.0 & 9.9 & 10.0 & 9.9 \\
\hline Rapeseed biodiesel(1g), $X_{3}$ & 0.0 & 0.0 & 2.3 & 0.1 & 0.0 & 0.1 \\
\hline Cellulosic ethanol(2g), $X_{4}$ & 2.2 & 2.3 & 2.3 & 5.0 & 5.0 & 5.0 \\
\hline Blt biodiesel(2g), $X_{5}$ & 5.0 & 5.0 & 5.0 & 5.0 & 5.0 & 5.0 \\
\hline Electricity, $\mathrm{X}_{6}$ & 10.0 & 10.0 & 10.0 & 10.0 & 10.0 & 10.0 \\
\hline CO2, index $=100$ if $100 \%$ fosil & 87.6 & 87.6 & 85.8 & 85.8 & 85.8 & 85.8 \\
\hline
\end{tabular}

Table 8.- Short-run portfolios for benchmark scenario at USD 0.0/ton CO2, MC-MV at USD 20/ton CO2 (variant 1) and MC-MV at USD 80/ton CO2 (variant 2), for USD 60/bbl and USD 120/bbl.

\begin{tabular}{|c|c|c|c|c|c|c|}
\hline & \multicolumn{6}{|c|}{ Long-run scenario (MC-MV efficiency mix) } \\
\hline & \multicolumn{3}{|c|}{ Low petroleum price } & \multicolumn{3}{|c|}{ High petroleum price } \\
\hline & $\begin{array}{c}\text { Benchmark } \\
\text { setting: } \\
\text { P CO2 }=0\end{array}$ & $\begin{array}{l}\text { Variant 1: } \\
\text { P CO2=20 }\end{array}$ & $\begin{array}{l}\text { Variant 2: } \\
\mathrm{P} \mathrm{CO} 2=80\end{array}$ & $\begin{array}{c}\text { Benchmark } \\
\text { setting: } \\
\text { P CO2=0 }\end{array}$ & $\begin{array}{l}\text { Variant 1: } \\
\text { P CO2=20 }\end{array}$ & $\begin{array}{l}\text { Variant 2: } \\
\text { P CO2=80 }\end{array}$ \\
\hline Cost,US\$/km & 0.0376 & 0.0412 & 0.0502 & 0.0616 & 0.0648 & 0.0738 \\
\hline Risk & 0.0738 & 0.0737 & 0.0716 & 0.09679 & 0.096 & 0.0913 \\
\hline Gaso-diesel, $\mathbf{X}_{1}$ & 25.0 & 25.0 & 25.0 & 25.0 & 25.0 & 25.0 \\
\hline Sugar cane ethanol(1g), $X_{2}$ & 0.0 & 0.0 & 0.0 & 24.5 & 25.3 & 22.6 \\
\hline Rapeseed biodiesel(1g), $X_{3}$ & 0.0 & 0.0 & 0.0 & 0.0 & 0.0 & 0.0 \\
\hline Cellulosic ethanol(2g), $\mathrm{X}_{4}$ & 16.5 & 15.4 & 14.5 & 18.8 & 21.3 & 28.5 \\
\hline Blt biodiesel(2g), $X_{5}$ & 13.4 & 17.3 & 18.1 & 3.4 & 13.9 & 23.8 \\
\hline Electricity, $\mathrm{x}_{6}$ & 45.1 & 42.4 & 42.4 & 28.3 & 14.5 & 0.0 \\
\hline $\mathrm{CO}$, index $=100$ if $100 \%$ fosil & 63.0 & 62.3 & 62.3 & 65.2 & 62.0 & 57.8 \\
\hline
\end{tabular}

Table 9.- Long-run portfolios for benchmark scenario at USD 0.0/ton CO2, MC-MV at USD 20/ton CO2 (variant 1) and MC-MV at USD 80/ton CO2 (variant 2), for USD 60/bbl and USD 120/bbl. 